\title{
PENDETEKSIAN TEPI OBJEK MENGGUNAKAN METODE GRADIEN
}

\author{
Dolly Indra \\ dolly.indra@umi.ac.id \\ Teknik Informatika Universitas Muslim Indonesia
}

\begin{abstract}
Abstrak
Pada tahap melakukan ekstraksi ciri (feature extraction) faktor yang sangat penting adalah kemampuan untuk mendeteksi keberadaan tepi di dalam citra. Tujuan penelitian ini adalah menggunakan konsep matematis untuk melakukan fungsi pendeteksian tepi. Uji coba yang dilakukan menggunakan matlab versi R2009a dengan menggunakan citra masukan berupa citra abu-abu (grayscale). Setiap citra diuji dengan menggunakan 3 cara yaitu menggunakan metode gradien citra, gradien Prewitt dan gradien Sobel. Cara kerja dari metode gradien terdiri dari gradien horizontal arah $\mathrm{x}$ menghasilkan tepi objek berupa garis vertikal dan diagonal dari citra input, gradien arah vertikal y menghasilkan tepi objek berupa garis horizontal dan diagonal dari citra input sedangkan total gradien merupakan gabungan dari gradien arah $\mathrm{x}$ dan gradien arah y sedangkan cara kerja dari untuk metode gradien Prewitt dan Sobel, pemilteran dilakukan secara parsial dengan arah yang berlawanan dengan arah fungsi turunan pertama, bila pemilteran dilakukan dalam arah y maka turunan pertama dari hasil pemilteran dilakukan dalam arah $\mathrm{x}$. Pendeteksian tepi menggunakan gradien Prewitt dan Sobel merupakan hasil gabungan dari konvolusi gradien Prewitt/Sobel arah $\mathrm{x}$ dengan gradien Prewitt/Sobel arah y. Hasil uji coba dari penelitian ini memperlihatkan bahwa pendeteksian tepi menggunakan gradien Sobel lebih tajam dibandingkan dengan gradien Prewitt dan gradien citra.
\end{abstract}

Kata kunci: Gradien, Prewitt, Sobel

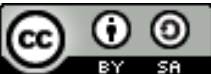

\section{Pendahuluan}

Pemrosesan gambar merupakan dasar dalam pengolahan citra (image processing) bisa berupa gambar (foto) maupun video. Mengubah citra dari sebuah gambar asli (original) digunakan untuk mempermudah pemrosesan persepsi mesin autonomous agar lebih mudah kedepannya untuk mengambil keputusan. Langkah yang sangat penting dalam pengolahan citra (image processing) adalah analisis citra (image analysis) yang bertujuan untuk mengidentifikasi parameter-parameter yang berkaitan dengan ciri (feature) dari objek didalam citra. Analisis citra terdiri dari 3 tahapan, yaitu ekstraksi ciri (feature extraction), segmentasi (segmentation) dan klasifikasi (classification). Faktor yang sangat penting dalam melakukan ekstrasi ciri adalah kemampuan untuk mendeteksi keberadaan tepi di dalam citra.

Dalam penelitian ini metode deteksi tepi yang digunakan adalah menggunakan gradien yang merupakan konsep matematis yang dikenal sebagai turunan pertama. Dengan menggunakan konsep ini dapat digunakan dalam fungsi pendeteksian tepi. Pendeteksian tepi merupakan tahapan untuk melingkupi informasi di dalam citra. Tepi mencirikan batas objek oleh karena itu tepi berguna untuk memproses segmentasi dan identifikasi objek di dalam suatu citra. Pendeteksian tepi yang dilakukan dalam penelitian ini ada 3 yaitu deteksi menggunakan gradien citra, gradien Prewitt dan gradien Sobel.

\section{Landasan Teori}

\subsection{Citra}

Citra (image) merupakan istilah lain untuk gambar sebagai salah satu komponen multimedia yang memegang peranan penting sebagai bentuk informasi virtual. Karakteristik suatu citra yaitu kaya dengan informasi. Citra adalah gambar pada bidang dua dimensi, ditinjau dari sudut matematis citra merupakan fungsi menerus (continues) dari intensitas cahaya pada bidang dua dimensi [1]. Citra ada dua yaitu citra diam dan citra bergerak. Citra diam adalah citra tunggal yang tidak bergerak disebut citra sementara citra bergerak adalah rangkaian citra diam yang ditampilkan secara berurutan (sekuensial) sehingga memberi kesan pada mata sebagai gambar yang bergerak. Setiap citra dalam rangkaian citra tersebut dinamakan dengan istilah frame. 


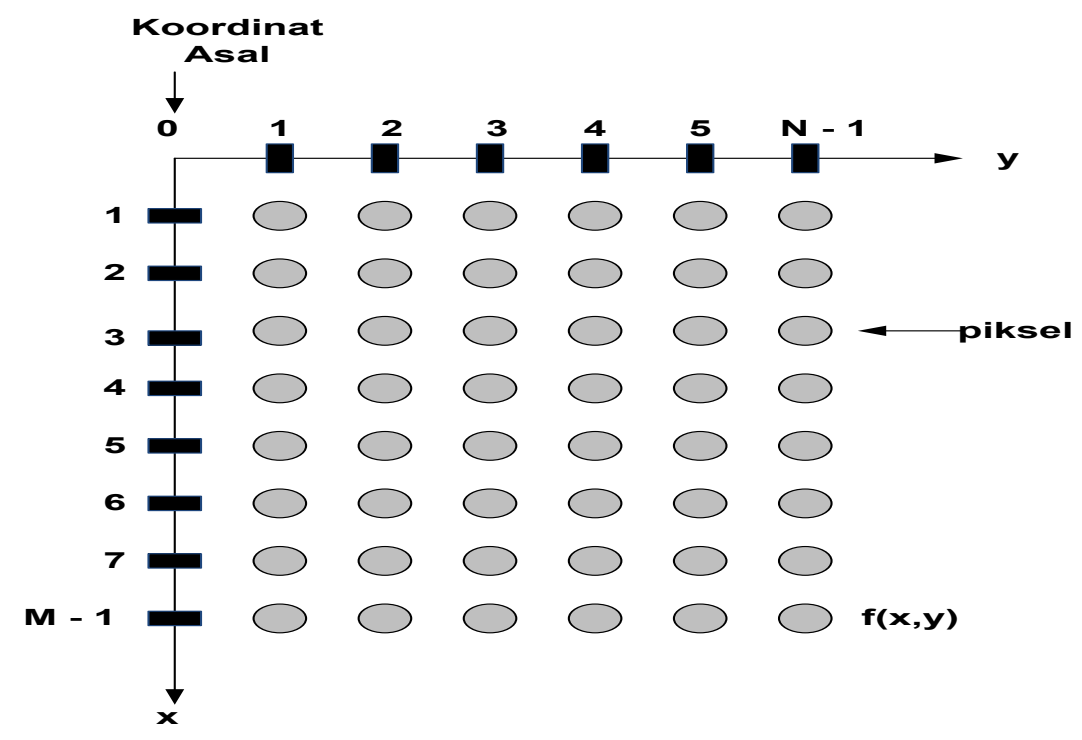

Gambar 1 Koordinat citra digital

\subsection{Citra Digital}

Citra digital dikelompokkan menjadi 4 macam [2], yaitu:

1. Citra RGB (Red, Green, Blue). Untuk citra RGB masing-masing pixel mempunyai sebuah warna khusus. Warna dideskripsikan oleh kombinasi komponen warna merah (Red), hijau (Green) dan biru (Blue) masing-masing komponen warna mempunyai range antara 0-255, sehingga total range warna yang digunakan untuk citra RGB adalah 16.777.216.

2. Citra abu-abu (Grayscale). Untuk citra abu-abu masing-masing pixel memiliki nilai normal 0 (hitam) sampai 255 (putih) yang dapat direpresentasikan oleh nilai 8 bit atau 1 byte.

3. Citra Biner. Setiap pixel hanya mempunyai warna hitam dan putih yang memiliki nilai 0 untuk hitam dan 1 untuk putih.

4. Indexed. Citra paling berwarna hanya memiliki sebagian kecil dari 16 juta kemungkinan warna. Untuk efisiensi storage dan kemudahan dalam handling file, sebuah gambar akan diasosiasikan dengan peta warna (color map) atau color pallete.

\subsection{Deteksi Tepi Objek}

Deteksi tepi (edge detection) pendekatan yang paling umum digunakan untuk mendeteksi diskontinuitas grey level [3]. Deteksi tepi merupakan sebuah operasi yang dijalankan untuk mendeteksi garis tepi atau batas untuk segmentasi atau identifikasi objek.

\subsection{Gradien}

Gradien merupakan turunan pertama yang dihitung sebagai akar pangkat dari jumlah kuadrat dari dua derivatif ( $x$ dan $y$ ) dan dinotasikan secara matematis sebagai persamaan 1 [4].

$$
\text { Gradien }=\sqrt{\left(\frac{\partial f}{\partial x}\right)^{2}+\left(\frac{\partial f}{\partial y}\right)^{2}}
$$

Turunan parsial pertama fungsi citra $\mathrm{I}(\mathrm{x}, \mathrm{y})$ terhadap sumbu $\mathrm{x}$ (horizontal) dan sumbu y (vertikal) diperoleh persamaan 2 gradien citra arah $\mathrm{x}$, persamaan 3 gradien citra arah y dan total gradien citra persamaan 4 [5].

$$
\begin{aligned}
& \nabla \mathrm{I}(x, y)_{x}=\frac{\partial \mathrm{I}}{\partial x}(x, y)=\mathrm{I}(x+1, y)-\mathrm{I}(x, y) \\
& \nabla \mathrm{I}(x, y)_{y}=\frac{\partial \mathrm{I}}{\partial y}(x, y)=\mathrm{I}(x, y+1)-\mathrm{I}(x, y)
\end{aligned}
$$




$$
\nabla \mathrm{I}(x, y)=\sqrt{\left(\nabla \mathrm{I}(x, y)_{x}\right)^{2}+\left(\nabla \mathrm{I}(x, y)_{y}\right)^{2}}
$$

\subsection{Operator Prewitt}

Deteksi tepi operator Prewitt diperkenalkan oleh Prewitt tahun 1970. Operator ini berbentuk matrik $3 \times 3$. Persamaan 5 , matrik operator Prewitt arah sumbu $x$, persamaan 6 , matrik operator Prewitt arah sumbu y dan Persamaan 7, gradien Prewitt [6].

$$
\begin{aligned}
G_{x} & =\left[\begin{array}{ccc}
-1 & -1 & -1 \\
0 & 0 & 0 \\
1 & 1 & 1
\end{array}\right] \\
G_{y} & =\left[\begin{array}{ccc}
-1 & 0 & 1 \\
-1 & 0 & 1 \\
-1 & 0 & 1
\end{array}\right] \\
G P & =\left|G_{x} * I\right|+\left|G_{y} * I\right|
\end{aligned}
$$

\subsection{Operator Sobel}

Deteksi tepi operator Sobel diperkenalkan oleh Irwin Sobel pada tahun 1970. Operator ini berbentuk matrik $3 \times 3$. Persamaan 8 , matrik operator Sobel arah sumbu $x$, persamaan 9, matrik operator Sobel arah sumbu y dan Persamaan 10, gradien Sobel [6]

$$
\begin{gathered}
G_{x}=\left[\begin{array}{ccc}
-1 & -2 & -1 \\
0 & 0 & 0 \\
1 & 2 & 1
\end{array}\right] \\
G_{y}=\left[\begin{array}{ccc}
-1 & 0 & 1 \\
-2 & 0 & 2 \\
-1 & 0 & 1
\end{array}\right] \\
G S=\left|G_{x} * I\right|+\left|G_{y} * I\right|
\end{gathered}
$$

\subsection{Matlab}

Matlab (Matrix laboratory) adalah sebuah perangkat lunak (software) yang digunakan untuk menganalisis data, melakukan prototyping matematis dan memvisualisasi tool dengan dukungan operasi matrik, mempunyai kemampuan grafis dan bahasa pemrograman yang digunakan termasuk kedalam bahasa pemrograman tingkat tinggi (high level language) [2].

\section{Metode}

\subsection{Tahapan Sistem Pendeteksi Tepi Objek}

Adapun tahapan sistem pendeteksi tepi objek (ditunjukkan pada gambar 2) terdiri dari yaitu 1. Input Citra berupa citra grayscale, 2 Deteksi Tepi Objek menggunakan 3 cara yaitu deteksi tepi objek menggunakan gradien citra, operator Prewitt dan operator Sobel.

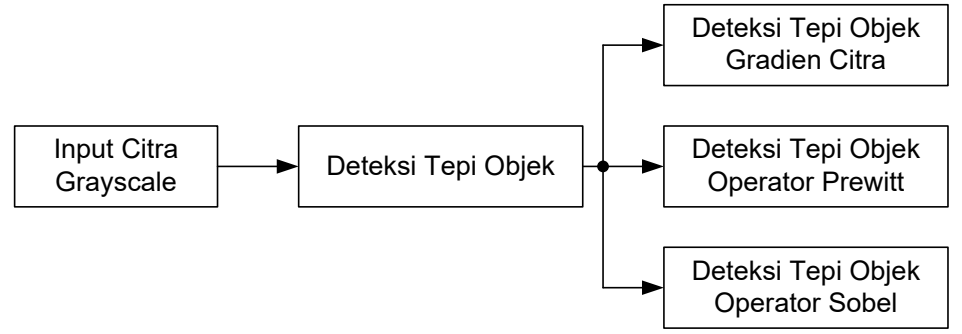

Gambar 2. Tahapan Sistem Pendeteksi Tepi Objek Keseluruhan Sistem 


\subsection{Metode Deteksi Gradien Citra}

Tahapan dalam mendeteksi tepi objek dengan menggunakan metode deteksi gradien citra ditunjukkan pada gambar 3 , yaitu :

a. Mulai.

b. Baca citra : Memanggil citra yang akan diolah yaitu citra RGB (Red, Green, Blue).

c. Konversi citra ke citra grayscale : Mengubah format citra dari citra RGB ke citra keabuan (grayscale).

d. Baca ukuran citra : Membaca citra baris dan kolomnya.

e. Hitung gradien arah $\mathrm{x}$ dan arah $\mathrm{y}$

- Gradien_arah_x (Piksel_baris,Piksel_kolom) = nilai absolut(citra( Piksel_baris+1,Piksel_kolom)-citra(Piksel_baris,Piksel_kolom)

- Gradien_arah_y_ (Piksel_baris,Piksel_kolom)_= nilai absolut(citra( Piksel_baris,Piksel_kolom+1)-citra(Piksel_baris,Piksel_kolom).

f. Hitung tōalal gradien citra :

- Total_gradien(Piksel_baris,Piksel_kolom) = sqrt(Gradien_arah_x (Piksel_baris,Piksel_kolom)^2 + Gradien_arah_y (Piksel_baris,Piksel_kolom)^2);

g. Tampilkan citra total gradien.

h. Selesai.

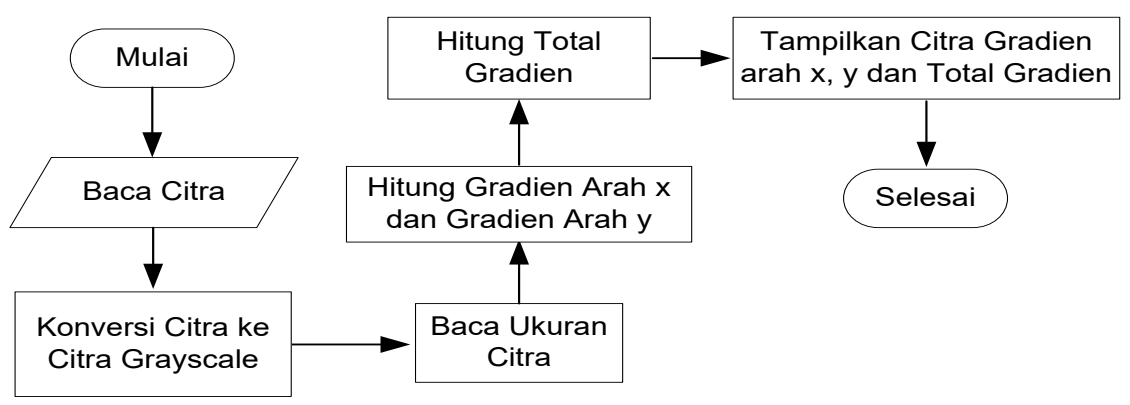

Gambar 3. Diagram Alir Deteksi Gradien Citra

\subsection{Metode Deteksi Gradien Prewitt dan Sobel}

Tahapan dalam mendeteksi tepi objek dengan menggunakan metode deteksi gradien Prewitt dan Sobel ditunjukkan pada gambar 4, yaitu :

a. Mulai.

b. Baca citra : Memanggil citra yang akan diolah yaitu citra RGB (Red, Green, Blue).

c. Konversi citra ke citra grayscale : Mengubah format citra dari citra RGB ke citra keabuan (grayscale).

d. Baca ukuran citra : Membaca citra baris dan kolomnya.

e. Pemberian nilai matrik operator Prewitt dan Sobel :

- Prewitt_arah_x $=[-1,-1,-1 ; 0,0,0 ; 1,1,1]$ dan Prewitt_arah_y $=[-1,0,1 ;-1,0,1 ;-1,0,1]$.

- Sobel_arah_ $\bar{x}=[-1,-2,-1 ; 0,0,0 ; 1,2,1]$ dan Sobel_arah_y $=[-1,0,1 ;-2,0,2 ;-1,0,1]$

f. Lakukan konvolusi pada operator Prewitt dan Sobel :

- Gradien_Prewitt_arah_x = konvolusi_2D (citra,Prewitt_arah_x, 'shape') dan Gradien_Prewitt_arah_y = konvolusi_2D (citra, Prewitt_arah_y, 'shape').

- Gradien_Sobel_arah_x = konvolusi_2D (citra,Sobel_ arah_x, 'shape') dan Gradien_Sobel_arah_y = konvolusi_2D (citra, Sobel_arah_y, 'shape').

g. Hitung gradien Prewitt dan Sobel :

- Gradien_Prewitt $=$ nilai_absolut(Gradien_Prewitt_arah_x $)+$ nilai_absolut (Gradien_Prewitt_arah_y);

- Gradien_Sobel = = nilai_absolut(Gradien_Sobel_arah_x $)+$ nilai_absolut (Gradien_Sobel_arah_y);

h. Tampilkan citra Prewitt dan Sobel.

i. Selesai 
ILKOM Jurnal Ilmiah Volume 8 Nomor 2 (Agustus 2016)

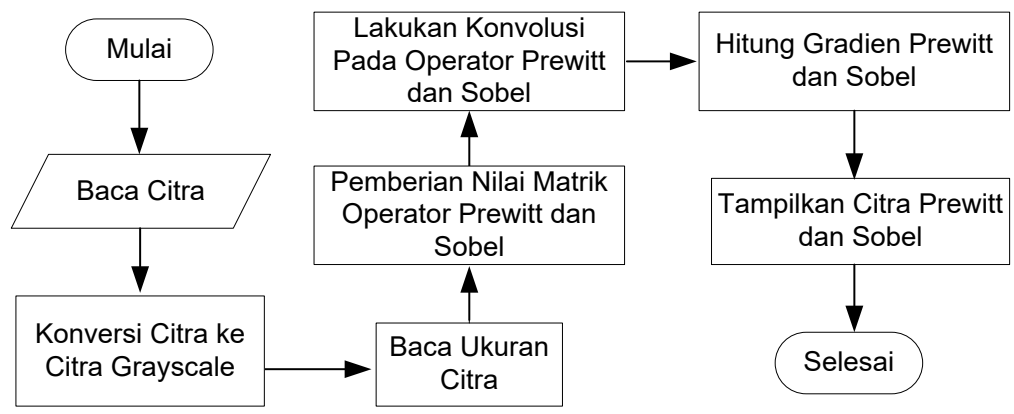

Gambar 4. Diagram Alir Deteksi Deteksi Gradien menggunakan Operator Prewitt dan Sobel

\section{Hasil}

Uji coba yang dilakukan menggunakan matlab versi R2009a dengan menggunakan citra masukan berupa citra abu-abu (grayscale). Setiap citra diuji dengan menggunakan 3 cara yaitu menggunakan metode gradien citra, gradien Prewitt dan gradien Sobel.

Hasil uji coba untuk metode gradien citra ditunjukkan pada tabel 1. Gradien arah $x$ menghasilkan tepi objek berupa garis vertikal dan diagonal dari citra input, gradien arah y menghasilkan tepi objek berupa garis horizontal dan diagonal dari citra input sedangkan total gradien merupakan gabungan dari gradien arah $\mathrm{x}$ dan gradien arah $\mathrm{y}$.

Tabel 1. Tabel Hasil Uji Coba Metode Deteksi Gradien Citra
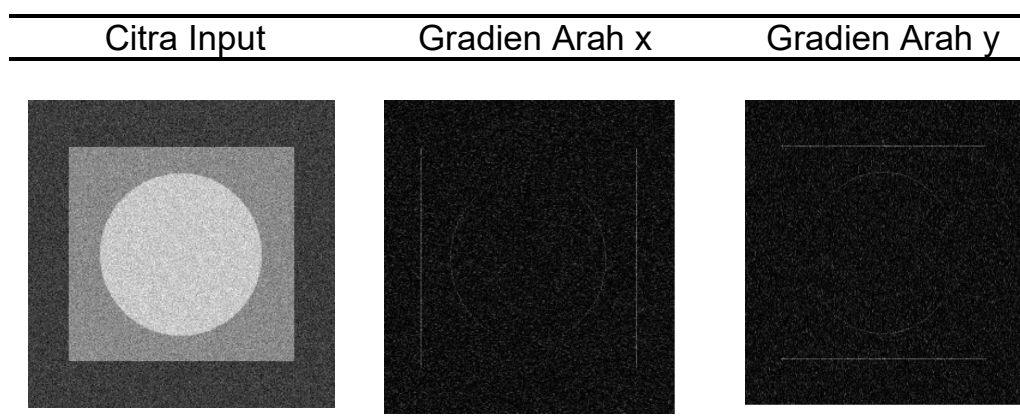

Total Gradien
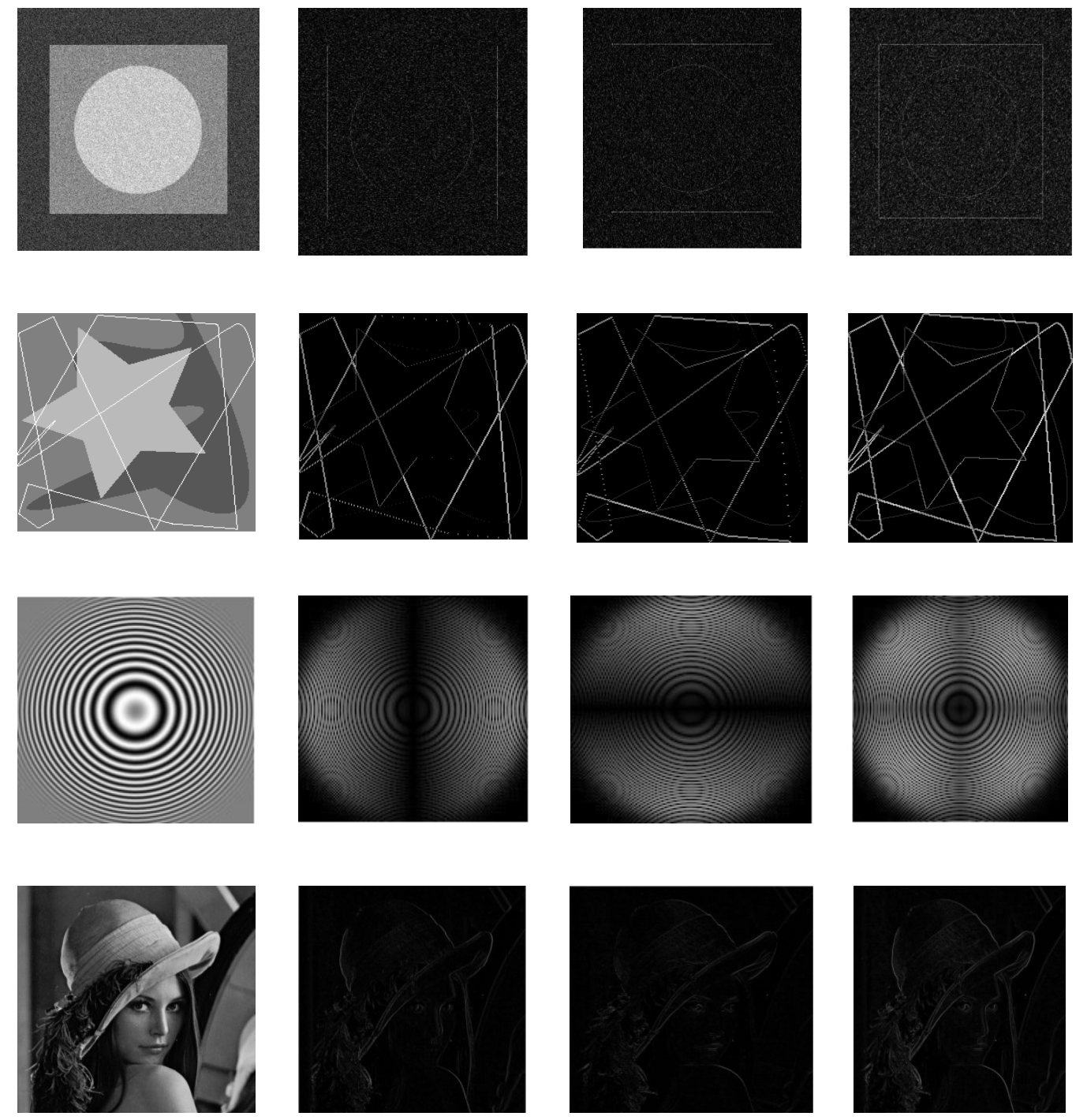
Hasil uji coba untuk metode gradien Prewitt dan Sobel ditunjukkan pada tabel 2. Gradien citra dari gradien Prewitt dan gradien Sobel merupakan hasil dari konvolusi citra input. Hasil gabungan dari konvolusi gradien Prewitt/Sobel arah x dengan gradien Prewitt/Sobel arah y.

Tabel 2. Tabel Hasil Uji Coba Metode Deteksi Gradien Prewitt dan Sobel
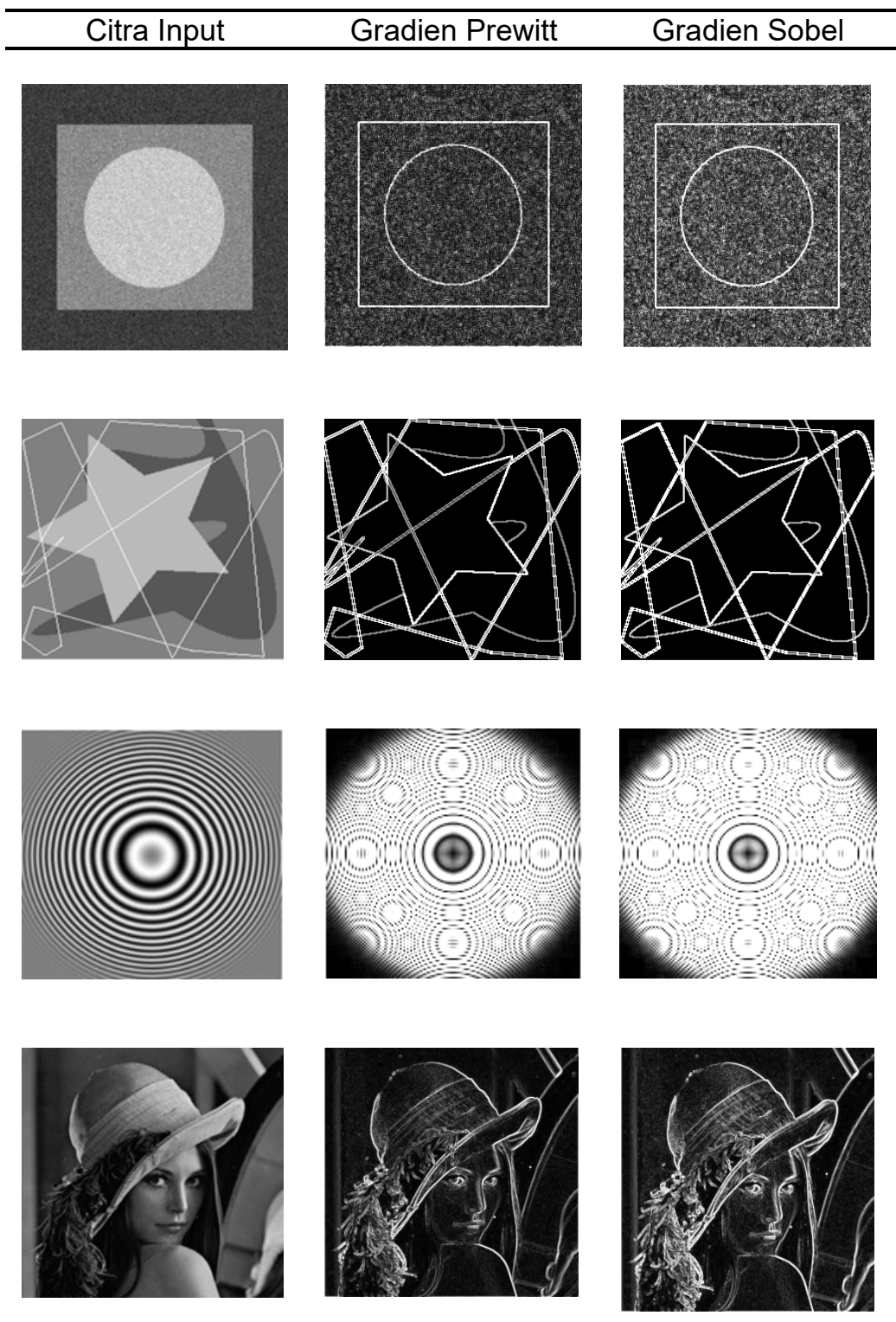

\section{Kesimpulan dan saran}

\subsection{Simpulan}

a. Deteksi menggunakan gradien citra merupakan hasil perhitungan gradien arah $\mathrm{x}$ dan arah y dimana gradien arah $\mathrm{x}$ memperlihatkan tepi objek yang terdeteksi adalah garis-garis vertikal dan diagonal sedangkan tepi berupa garis-garis horizontal tidak terdeteksi, sementara gradien arah y memperlihatkan tepi objek yang terdeteksi adalah garis-garis horizontal dan diagonal sedangkan tepi berupa garis-garis vertikal tidak terdeteksi.

b. pemilteran pada gradien Sobel dan Prewitt dilakukan secara parsial dengan arah yang berlawanan dengan arah fungsi turunan pertama, bila pemilteran dilakukan dalam arah y maka turunan pertama dari hasil pemilteran dilakukan dalam arah x. Deteksi menggunakan gradien Prewitt dan Sobel merupakan hasil gabungan dari konvolusi gradien Prewitt/Sobel arah $\mathrm{x}$ dengan gradien Prewitt/Sobel arah y.

c. Deteksi tepi menggunakan gradien Sobel lebih tajam dibandingkan dengan gradien Prewitt dan gradien citra. 


\subsection{Saran}

a. Hasil dari pendeteksian tepi objek dapat digunakan pada tahap berikutnya yaitu segmentasi untuk mereduksi citra menjadi objek atau region.

b. Pendeteksian tepi objek dengan menggunakan operator lain untuk membandingkan dengan hasil dari penelitian ini untuk memperoleh metode yang optimal agar supaya deteksi tepi objek lebih sempurna.

\section{Daftar Pustaka}

[1] Apriliani. D dan Murinto. 2013. Analisis Perbandingan Teknik Segmentasi Citra Digital Menggunakan Metode Level-Set Chan \& Vese Dan Lankton, Jurnal Sarjana Teknik Informatika, Volume 1 Nomor 1, Juni 2013, pp: 232-240.

[2] Wahana Komputer, 2013. Ragam Aplikasi Pengolahan Image dengan Matlab, PT Elex Media Komputindo, Jakarta.

[3] Wijaya. E. 2012. Analisis Intensitas Metode Pendeteksian Tepi Sobel, Jurnal Komputer dan Informatika (KOMPUTA), Edisi I, Volume 1, Maret 2012, pp: 25-27.

[4] Yulian Fauzi. 2005. Implementasi Algoritma Filtering Derivatif Dalam Mengolah Citra Satelit Pada Software Envi, Jurnal Gradien Vol.1 No.2, Maret 2005, pp:81-86.

[5] Madenda. S. 2015. Pengolahan Citra \& Video Digital : Teori, Aplikasi dan Pemrograman Menggunakan Matlab, Erlangga, Jakarta.

[6] Gonzales, R.C. and Woods, R.E. 2002. Digital Image Processing. Second Edition. Prentice-Hall.

[7] Arif Sutikno, Ema Utami, Andi Sunyoto. 2014. Penerapan Metode Morfologi Gradien untuk Perbaikan Kualitas Deteksi Tepi pada Citra Motif Batik, Jurnal Teknologi Informasi, Vol. IX, No. 25, Maret 2014 